\title{
An Ecological Assessment of Critically Endangered Chinese Pangolin Manis pentadactyla (Mammalia: Pholidota: Manidae) in the Midhills Region of Nepal
}

\author{
Sandeep Shrestha ${ }^{1 *}{ }^{\circledR}$, Ashish Bashyal2 ${ }^{2}$ Rojeena Rijal1, Janam Shrestha1, Palistha Shrestha1, \\ Nischal Shrestha' ${ }^{2}$, Thomas J. McGreevy Jr. ${ }^{3}$, Bill Buffum ${ }^{3}$, Sanjay Nath Khanal ${ }^{1}$ \\ ${ }^{1}$ Department of Environmental Science and Engineering, Kathmandu University, Dhulikhel, Nepal \\ ${ }^{2}$ Biodiversity Conservancy Nepal, Butwal, Nepal \\ ${ }^{3}$ Department of Natural Resources Science, University of Rhode Island, Kingston, RI, USA \\ Email: *sandeep@ku.edu.np
}

How to cite this paper: Shrestha, S., Bashyal, A., Rijal, R., Shrestha, J., Shrestha, P., Shrestha, N., McGreevy Jr., T.J., Buffum, B. and Khanal, S.N. (2021) An Ecological Assessment of Critically Endangered Chinese Pangolin Manis pentadactyla (Mammalia: Pholidota: Manidae) in the Midhills Region of Nepal. Open Journal of Ecology, 11, 344-356.

https://doi.org/10.4236/oje.2021.114024

Received: March 20, 2021

Accepted: April 18, 2021

Published: April 21, 2021

Copyright $\odot 2021$ by author(s) and Scientific Research Publishing Inc. This work is licensed under the Creative Commons Attribution International License (CC BY 4.0).

http://creativecommons.org/licenses/by/4.0/ (c) (i) Open Access

\begin{abstract}
The Chinese Pangolin (Manis pentadactyla) is a "Critically Endangered" insectivorous mammal. There is a lack of information on the ecology, distribution and behavior of this species in Nepal, even though community forests in the Midhills Region of Nepal are considered to be prime habitats for the species. We conducted an ecological assessment of the habitat use of this species in nine community forests covering an area of 170.69 ha in Balthali village in Kavrepalanchok district, Nepal. We divided each forest into $50 \times 50$ m grids and searched for Chinese Pangolin burrows along $50 \mathrm{~m}$ transects in each grid. We categorized burrows into two types, new and old burrows, and recorded 10 environmental variables for each burrow. We found a total of 542 burrows, including 323 old burrows and 219 new burrows. The average width and height of a burrow opening was $21.66 \pm 3.94 \mathrm{~cm}(n=542)$ and $22.42 \pm 5.02 \mathrm{~cm}(n=$ 542). The total density of burrows in the study area was $3.1 \mathrm{ha}^{-1}$, with new burrows density of $1.2 \mathrm{ha}^{-1}$ and old burrows density of $1.8 \mathrm{ha}^{-1}$. We found most burrows in sites with an elevation range of $1400-1500 \mathrm{~m}$ above sea level, gentle slopes, brown colored soil, high density of tree crown cover and undergrowth vegetation, southern exposure, within $150 \mathrm{~m}$ from a water source and less than $200 \mathrm{~m}$ from a human settlement. Our study has generated baseline data on the habitat use of Chinese Pangolin, which we hope will help in designing site-specific action plans for Chinese Pangolin conservation in Kavrepalanchok district, Nepal.
\end{abstract}




\section{Keywords}

Burrow, Community Forest, Conservation, Density, Habitat

\section{Introduction}

The Chinese Pangolin (Manis pentadactyla) is a small burrowing insectivorous mammal found in China, Hong Kong, India, Lao People's Democratic Republic, Myanmar, Nepal, Thailand, Bangladesh, Vietnam and Bhutan [1]. The species is listed as "Critically Endangered" on the International Union for Conservation of Nature Red List of Threatened Species [1]. The Chinese Pangolin is one of the most illegally trafficked species in the world due to the high economic value of its scales and meat [2] [3] and it is listed in Appendix I of the Convention on International Trade in Endangered Species of Wild Fauna and Flora [4]. In Nepal, the Chinese Pangolin is protected by the National Parks and Wildlife Conservation Act of 1973, but illegal hunting and trapping is common for export as well as for local consumption and traditional medicine [5] [6]. However, the first Pangolin Park in Nepal has recently been established and the growing interest in this species and the potential benefits from ecotourism will hopefully support its conservation [7].

Chinese Pangolins excavate burrows to search for termites, as well as for resting locations to avoid the cold weather [8] [9]. The locations of their burrows during different seasons can indicate habitat preference in terms of the environmental variables existing in the area [10]. Understanding the importance of environmental variables such as elevation, crown cover, undergrowth vegetation, slope, aspect, distance from water source and human settlement is vital for conservation planning for the species [10] [11] [12]. Pangolins occupy a variety of habitats within their geographical range [12], so the design and implementation of a conservation strategy for this endangered species require a thorough knowledge of their population and habitat ecology [1]. In Nepal, the geographic distribution, population size and status of Chinese Pangolins remain poorly understood as few studies have been carried out in the country [5] [6] [13] [14] [15] [16] [17] [18]. The aim of our study was to increase the understanding of Chinese Pangolin's habitat use in Nepal by assessing their burrow locations in nine community forests in Nepal.

\section{Materials and Methods}

\subsection{Study Area}

We conducted the study in Balthali village $\left(27.54^{\circ} \mathrm{N}\right.$ and $\left.85.54^{\circ} \mathrm{E}\right)$ situated in Panuati Municipality in Kavrepalanchok district, Province 3, Nepal (Figure 1). The district covers an area of 1396 sq. km having a subtropical climate and elevation ranging from 280 - 3018 meters above sea level. Balthali village is mostly covered with terraced farmland, but also includes a number of community fo- 
rests. Nepal has an active community forestry program, which gives communities authority to manage national forests near their villages; this program is recognized as providing a range of economic and social benefits to communities, including reducing conflict with wildlife [19]. The community forests in Balthali village are dominated by tree species like Pinus roxburghii, Prunus cerasoides, Rhododendron spp., Alnus nepalensis, Choerospondias axillaris and Schima wallichii. There were many community forests in a Balthali village, so before selecting the study sites we communicated with District forest officers (DFO) for information on the presence of Chinese Pangolins in these community forests. We further verified information provided by DFOs through meetings with each community forest user groups and our preliminary field observations. We then selected nine community forests having an altitude range of $1300-1600 \mathrm{~m}$ in Balthali village: Kamaladevi, Dhadko Ban, Dhungana Danda, Thulochaur, Timalkot, Sanu Gaun, Padhero, Silinge Bheer and Kol Bhanjyang, comprising a total area of 170.69 ha (Figure 1; Table 1).

\subsection{Methods}

We conducted our field surveys from 27 March 2019 to 3 May 2019. We investigated habitat use of Chinese Pangolins by counting burrows in nine community forests and recording environmental variables at each burrow. Chinese Pangolin sightings in the wild are very rare due to its nocturnal behavior and habit of remaining in burrows during the day [10]. Chinese Pangolins satisfy their

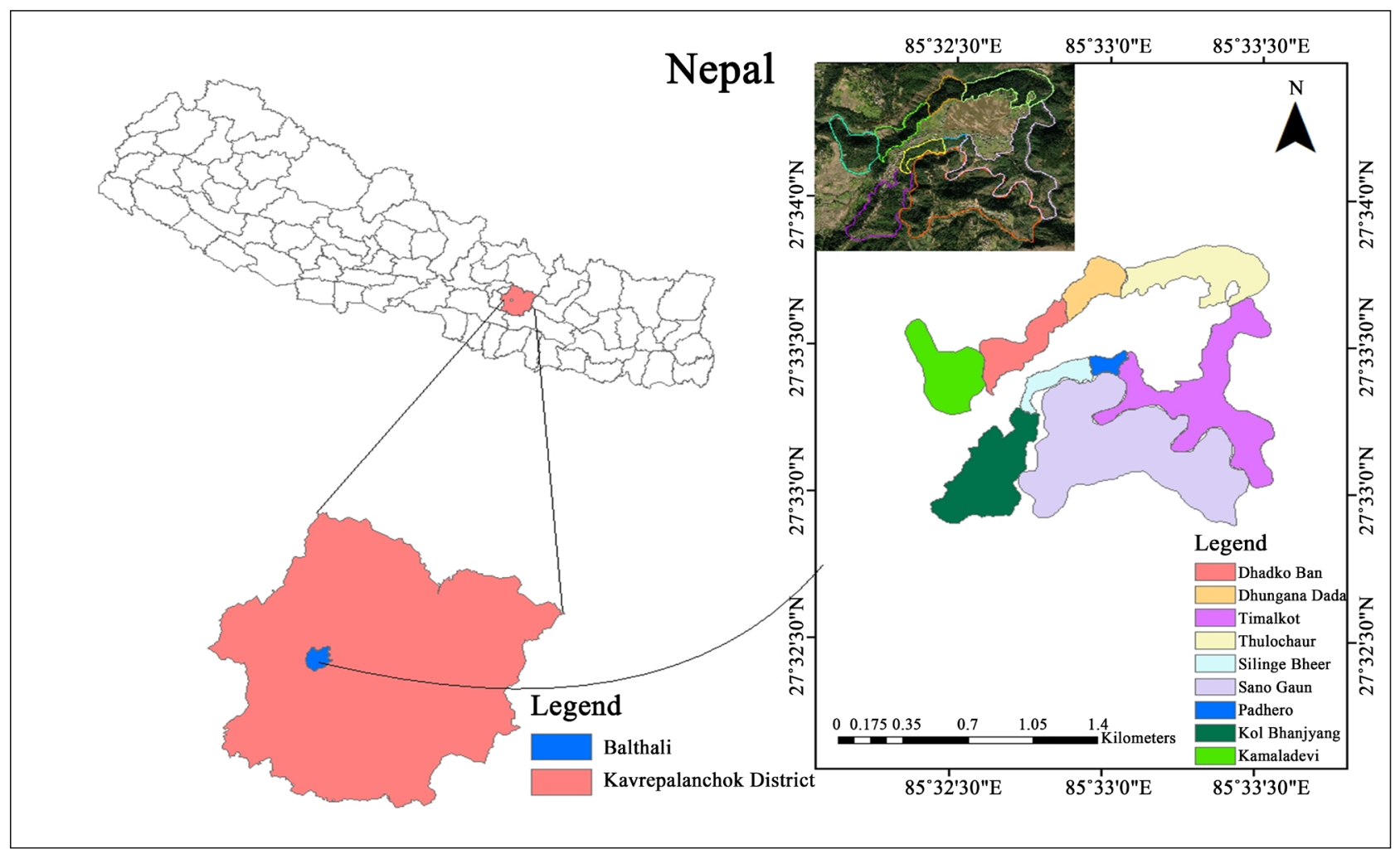

Figure 1. The study area showing nine community forests in Balthali village, Kavrepalanchok district, Nepal. 
requirements for food, concealment and temperature by digging and living in burrows for two to seven day periods [3], therefore, burrow count methods have been widely used in assessing Chinese Pangolin status and distribution in Nepal [5] [11] [16] [20], Bhutan [21] and China [10] [22].

In each community forest, we walked along the boundary and recorded the boundary's Geographic Position System (GPS) coordinates using a handheld Garmin GPS Map 60 CSx. We processed the boundary coordinates using Arc GIS 10.5 (Environmental Systems Research Institute, Redlands, CA) and prepared a shapefile for each community forest. We mapped $50 \mathrm{~m} \times 50 \mathrm{~m}$ grids in each community forest using the ArcGIS fishnet tool. The number of grids created was based on the area of the given community forests. We visited each grid and laid out a $50 \mathrm{~m}$ transect through the center of the grid. Then we searched for Chinese Pangolin burrows and counted the burrows on both sides within 25 $\mathrm{m}$ of the line transect.

Community forests have other borrowing animals including porcupines ( $\mathrm{Hy}$ strix spp.), whose burrows look somewhat similar to that of Chinese Pangolins. Porcupine burrows generally have dual entrances and burrows are interconnected with porcupine needles present at the burrow entrances. We identified the Chinese Pangolin burrows using criteria such as larger burrow size (over 15 $\mathrm{cm}$ wide and over $50 \mathrm{~cm}$ deep) and by observing verifiable clues like burrow shape, scratches, foot marks, tail drags, and presence of termites and ants in and around the burrows. The Pangolin Monitoring Guideline for Nepal [20] has recommended similar criteria for identifying Chinese Pangolin burrows. In Nepal, Indian Pangolin (Manis crassicaudata) are recorded in seven districts of lowland Terai and they are found to have sympatric distribution with Chinese Pangolins only in two districts-Chitwan and Parsa [20]. Our study area which is situated in central mid-hill region of Nepal is well outside the Indian Pangolin range [20]. Thus, all the burrows identified originated from Chinese Pangolin.

We recorded the GPS location of each Chinese Pangolin burrow encountered along transects using a handheld Garmin GPS Map 60 CSx. We measured the height and width of the burrow opening using a measuring tape. We categorized the Chinese Pangolin burrows into two types following the Pangolin Monitoring Guideline for Nepal [20]: New burrows which were still actively used and old burrows, which were no longer being used. In New burrows, we observed freshly dug soil with fresh footmarks, no dry fodder and seedling vegetation in burrows and presence of many fresh scratches. In old burrows, we observed compact and dry soils with presence of spider webs and burrow entrances fully covered by grasses, smaller branches and dried leaves.

The burrow locations of Chinese Pangolins indicate their preference for particular habitats [10] [23]. To investigate this, we assessed 10 environmental attributes at each burrow. We recorded the elevation with the handheld Garmin GPS Map $60 \mathrm{CS} x$. We recorded the forest canopy cover with a spherical densiometer (Model-A, Lemmon). We recorded the slope with a clinometer (Sokkia Abney Level 
Clinometer) and the burrow aspect with a compass (Silva Expedition 4 Compass). We assessed the soil colour in each burrow with a Munsell soil color chart. We assessed soil moisture with a MS300 Digital Moisture Meter by taking three soil moisture readings at each burrow and recording the average value. We assessed the percentage of ground vegetation in a $1 \mathrm{~m} \times 1 \mathrm{~m}$ quadrant at the center of the burrow opening. We recorded the temperature inside and outside the burrows with an infrared thermometer. The thermometer measured the inside of the burrow's temperature at the point where the infrared light hit the bending of the burrow. We calculated the linear distance to the nearest river water source and human settlement (Balthali village) by using Google Earth Pro software. We determined the environmental factors used by Chinese Pangolins using the approach of $\mathrm{Wu}$ et al. [10] where high values of an environmental variable's occurrence frequency $\left(P_{0}\right)$ indicates higher use for specific environmental variables.

$$
P_{0}=\left(\frac{\text { Frequency of occurrence of a specific habitat feature }}{\text { Total number of burrows observed }}\right) \times 100
$$

\section{Results}

We surveyed 679 transects and found burrows in $16.9 \%$ of them (Figure 2). We recorded a total of 542 burrows in our nine study sites (Table 1; Figure 2). We classified 219 burrows as New/active and 323 burrows as Old/inactive. The total density of burrows in the study area was $3.1 \mathrm{ha}^{-1}$. The density of new burrows was $1.2 \mathrm{ha}^{-1}$ and the density of old burrows was $1.8 \mathrm{ha}^{-1}$. There was considerable variation in burrow density between the nine sites. The highest burrow density was recorded in Kamaladevi CF with $11.9 \mathrm{ha}^{-1}$ and the lowest burrow density was recorded in SanuGaun CF with $0.38 \mathrm{ha}^{-1}$ (Table 1).

Table 1. Summary of occurrence of total burrows including new and old burrows and their respective density in nine community forests in Balthali village in Kavrepalanchok district, Nepal.

\begin{tabular}{cccccccc}
\hline $\begin{array}{c}\text { Community } \\
\text { Forest }\end{array}$ & $\begin{array}{c}\text { Area } \\
\text { (ha) }\end{array}$ & $\begin{array}{c}\text { New } \\
\text { Burrow }\end{array}$ & $\begin{array}{c}\text { New Burrow } \\
\text { Density ha }{ }^{-1}\end{array}$ & $\begin{array}{c}\text { Old } \\
\text { Burrow }\end{array}$ & $\begin{array}{c}\text { Old Burrow } \\
\text { Density ha }{ }^{-1}\end{array}$ & $\begin{array}{c}\text { Total } \\
\text { Burrow }\end{array}$ & $\begin{array}{c}\text { Total } \\
\text { Density ha }\end{array}$ \\
\hline Kamaladevi & 14 & 109 & 7.79 & 58 & 4.14 & 167 & 11.93 \\
Dhadko Ban & 9.78 & 7 & 0.72 & 48 & 4.91 & 55 & 5.62 \\
Dhungana Danda & 6.96 & 10 & 1.44 & 45 & 6.47 & 55 & 7.90 \\
Thulochaur & 18.6 & 51 & 2.74 & 78 & 4.19 & 129 & 6.94 \\
Timalkot & 33.4 & 10 & 0.30 & 39 & 1.17 & 49 & 1.47 \\
Sanu Gaun & 60.3 & 12 & 0.20 & 11 & 0.18 & 23 & 0.38 \\
Padhero & 1.88 & 0 & 0.00 & 7 & 3.72 & 7 & 3.72 \\
Silinge Bheer & 4.77 & 2 & 0.42 & 15 & 3.14 & 17 & 3.56 \\
Kol Bhanjyang & 21 & 18 & 0.86 & 22 & 1.05 & 40 & 1.90 \\
Overall & 170.69 & 219 & 1.28 & 323 & 1.89 & 542 & 3.17 \\
\hline
\end{tabular}




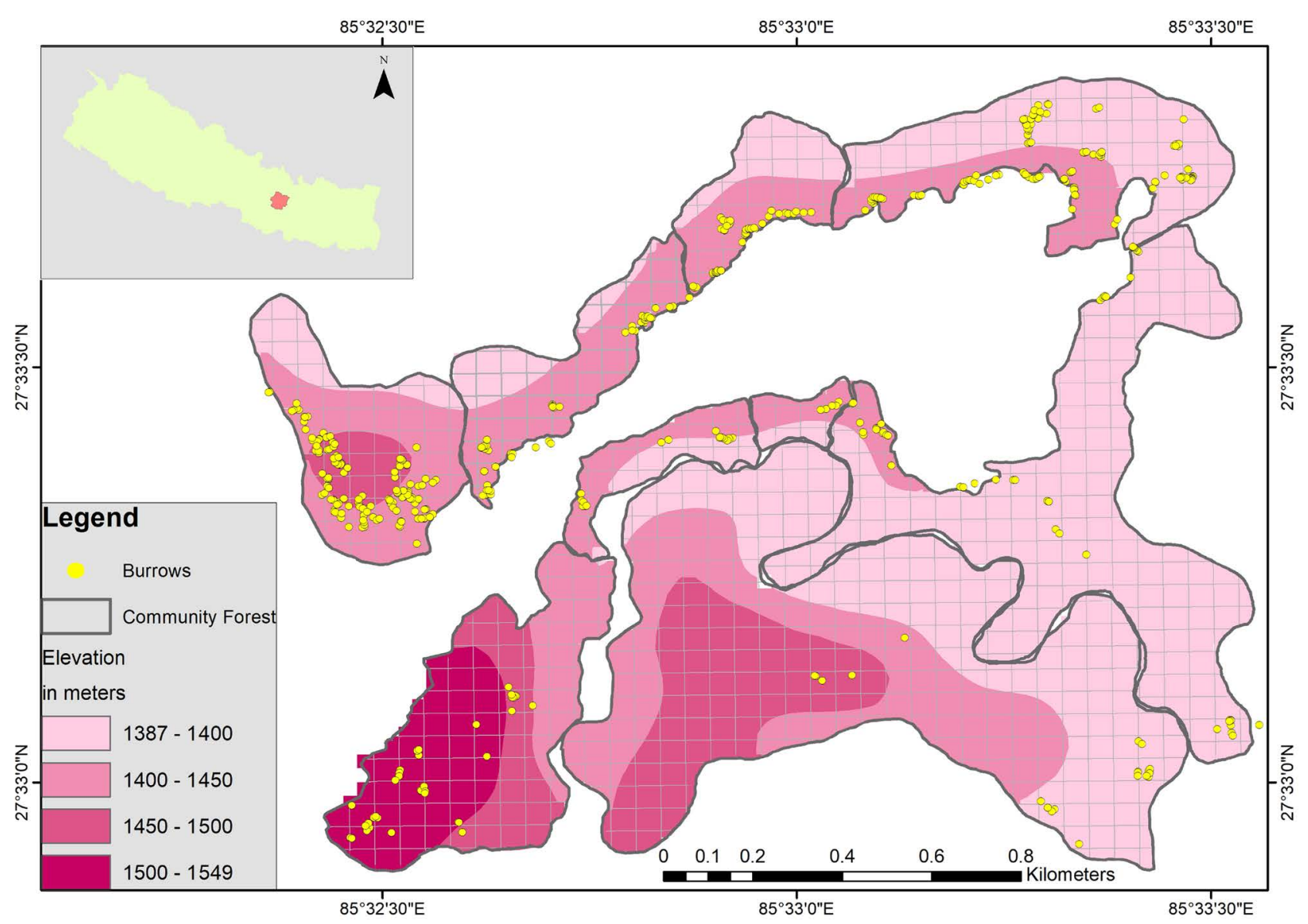

Figure 2. Burrows of Chinese Pangolins (Manis pentadactyla) recorded at different elevations in nine community forests in Balthali village, Kavrepalanchok district, Nepal.

The average width of all Chinese Pangolin burrows was $21.66 \pm 3.94 \mathrm{~cm}(n=$ $542)$ and the average height was $22.42 \pm 5.02 \mathrm{~cm}(n=542)$. The average width was $21.35 \pm 3.28 \mathrm{~cm}(n=219)$ for New burrows and $21.79 \pm 3.68 \mathrm{~cm}(n=323)$ for old burrows. The average height was $22.13 \pm 4.51 \mathrm{~cm}(n=219)$ for New burrows and $22.20 \pm 4.99 \mathrm{~cm}(n=323)$ for old burrows.

We measured 10 environmental variables associated with burrows and the occurrence frequency $\left(\mathrm{P}_{\mathrm{o}}\right)$ of each environmental variable (Table 2). We recorded the highest frequency $(76 \%)$ of burrows in the middle elevation rage (1401 - $1500 \mathrm{~m})$, followed by $16 \%$ in the low elevation range $(1300-1400 \mathrm{~m})$ and $8 \%$ burrows in the highest elevation range (1501 - $1559 \mathrm{~m}$; Figure 2). We found most burrows $(91 \%)$ in gentle slopes $<30^{\circ}$ (Table 2 ). We did not find any burrows on very steep slopes $>60^{\circ}$. Most burrows were oriented in a southernly rather than a northernly direction. The highest percentage $(21 \%)$ of burrow entrances was oriented in the Southeast direction, while the lowest percentage (3\%) was oriented in the North direction. The descending order was Southeast $(21 \%)>$ South $(19 \%)>$ East $(16 \%)>$ West $(16 \%)>$ Southwest $(15 \%)>$ Northwest $(6 \%)>$ Northeast $(5 \%)>$ North $(3 \%)$.

Most burrows (48\%) were in sites with high forest canopy density, and very 
Table 2. Occurrence frequency of different environmental variables recorded in Chinese Pangolin Burrows.

\begin{tabular}{|c|c|c|c|c|c|}
\hline Environmental Variables & Sub-Category & New Burrows & Old Burrows & Total Burrows & $P_{o}(\%)$ \\
\hline \multirow{3}{*}{ Elevation } & Low: $1309-1400 \mathrm{~m}$ & 42 & 44 & 86 & 15.87 \\
\hline & Moderate: $1401-1500 \mathrm{~m}$ & 158 & 254 & 412 & 76.01 \\
\hline & High: $1501-1559 \mathrm{~m}$ & 19 & 25 & 44 & 8.12 \\
\hline \multirow{3}{*}{ Canopy Closure } & Low: $0 \%-30 \%$ & 36 & 60 & 96 & 17.71 \\
\hline & Medium: $31 \%-70 \%$ & 54 & 133 & 187 & 34.50 \\
\hline & High: $71 \%-100 \%$ & 129 & 130 & 259 & 47.79 \\
\hline \multirow{3}{*}{ Undergrowth Vegetation } & Low: $0 \%-30 \%$ & 32 & 67 & 99 & 18.27 \\
\hline & Medium: $31 \%-70 \%$ & 74 & 123 & 197 & 36.35 \\
\hline & High: $71 \%-100 \%$ & 113 & 133 & 246 & 45.39 \\
\hline \multirow{2}{*}{$\begin{array}{l}\text { Distance to Nearest } \\
\text { Human Settlement }\end{array}$} & $<200 \mathrm{~m}$ & 188 & 290 & 478 & 88.19 \\
\hline & $>200 \mathrm{~m}$ & 31 & 33 & 64 & 11.81 \\
\hline \multirow{2}{*}{$\begin{array}{c}\text { Distance to Nearest } \\
\text { Water Source }\end{array}$} & $<150 \mathrm{~m}$ & 141 & 215 & 356 & 65.68 \\
\hline & $>150 \mathrm{~m}$ & 78 & 108 & 186 & 34.32 \\
\hline \multirow{3}{*}{ Slope Gradient } & Gentle Slope: $<30^{\circ}$ & 207 & 286 & 493 & 90.96 \\
\hline & Steep Slope: $30^{\circ}-60^{\circ}$ & 12 & 37 & 49 & 9.04 \\
\hline & Very Steep Slope: $>61^{\circ}$ & 0 & 0 & 0 & 0.00 \\
\hline \multirow{8}{*}{$\begin{array}{l}\text { Burrow Orientation } \\
\text { (Aspect) }\end{array}$} & East & 35 & 52 & 87 & 16.05 \\
\hline & North & 3 & 13 & 16 & 2.95 \\
\hline & North East & 13 & 15 & 28 & 5.17 \\
\hline & North West & 6 & 24 & 30 & 5.54 \\
\hline & South & 45 & 57 & 102 & 18.82 \\
\hline & South East & 43 & 69 & 112 & 20.66 \\
\hline & South West & 35 & 47 & 82 & 15.13 \\
\hline & West & 39 & 46 & 85 & 15.68 \\
\hline \multirow{3}{*}{ Soil Moisture } & $0 \%-15 \%$ & 166 & 217 & 383 & 70.66 \\
\hline & $15 \%-30 \%$ & 42 & 91 & 133 & 24.54 \\
\hline & $>30 \%$ & 11 & 15 & 26 & 4.80 \\
\hline \multirow{7}{*}{ Soil Color } & Brown & 79 & 95 & 174 & 32.10 \\
\hline & Light Brown & 38 & 141 & 179 & 33.03 \\
\hline & Dark Brown & 11 & 60 & 71 & 13.10 \\
\hline & Red & 6 & 0 & 6 & 1.11 \\
\hline & Reddish Brown & 44 & 11 & 55 & 10.15 \\
\hline & Yellow & 6 & 1 & 7 & 1.29 \\
\hline & Yellowish Brown & 35 & 15 & 50 & 9.23 \\
\hline \multirow{2}{*}{ Temperature inside Burrow } & $<20^{\circ} \mathrm{C}$ & 205 & 283 & 488 & 90.04 \\
\hline & $>20^{\circ} \mathrm{C}$ & 14 & 40 & 54 & 9.96 \\
\hline \multirow{2}{*}{$\begin{array}{c}\text { Temperature outside } \\
\text { Burrow }\end{array}$} & $<20^{\circ} \mathrm{C}$ & 113 & 133 & 246 & 45.39 \\
\hline & $>20^{\circ} \mathrm{C}$ & 106 & 190 & 296 & 54.61 \\
\hline
\end{tabular}


few burrows (18\%) were in sites with low forest canopy density. Similarly, most burrows (45\%) were in sites with high undergrowth vegetation density, and fewer (18\%) were in sites with low density. Most burrows (88\%) were less than 200 $\mathrm{m}$ from the nearest human settlement and this trend was common for both new and old burrows (Table 2).

Almost all burrows (99\%) were found in brown soil and only $1 \%$ of burrows were recorded in red soil. We further classified the brown soil color and found the percentage order of soil color as: Light brown $>$ Brown $>$ Dark brown $>$ Reddish brown $>$ Yellowish brown $>$ Red soil (Table 2). Most burrows (71\%) had low soil moisture of $15 \%$ or less. The temperatures inside the burrows were lower than outside. Most burrows (90\%) had an internal temperature less than $20^{\circ} \mathrm{C}$ and only $45 \%$ of the burrows had an external temperatures less than $20^{\circ} \mathrm{C}$ (Table 2).

\section{Discussion}

We investigated habitat use by Chinese Pangolins by counting burrows in nine community forests in Balthali village, Nepal, and recording 10 environmental variables at each burrow. We categorized Chinese Pangolins burrows into two types: New/active burrows and old/inactive burrows. Our findings confirm the findings of other studies that the average diameter of burrows is $15-20 \mathrm{~cm} \mathrm{[2]}$ [20] [22] and Heath [2] has shown that the burrows widen into larger chambers behind the openings. Around each new burrow, we observed numerous incompletely dug smaller burrows with shallower openings and less depth with presence of ants and termites, which we classified as feeding burrows. Chinese Pangolins dig burrows for living (resident) and feeding purposes [24]. Chinese Pangolins stay in the living burrows and will forage in an area $50-100 \mathrm{~cm}$ in circumference around their living burrows for several days [2]. Chinese Pangolin digs a hole (5 - $10 \mathrm{~cm}$ deep) as latrine sites to deposit urine and feces and cover the hole with soil [2] [24]. Chinese Pangolins burrow depths differ in summer and winter due to differences in termite distributions [2] [22] and burrow opening diameter is dependent on the body size of the pangolin residing in the living burrow [12]. We did not find differences in burrow opening width and height between new and old burrows, whereas Karawita et al. [12] reported that the burrow width, height and depth of a related species (Indian Pangolin) differed between resting and feeding burrows. The Chinese Pangolin's living burrow design includes a $30^{\circ}$ upward sloping tunnel [25] whereas, the Indian Pangolin's living burrow design includes a $10^{\circ}-20^{\circ}$ downward sloping tunnel [12].

We recorded Chinese Pangolins burrows in nine community forests, and there was considerable variation in burrow density between community forests. Anthropogenic activities like livestock grazing, guard dogs, hunting inside community forests, forest fire and construction of foot trails could result in detrimental effects on Chinese Pangolin survival [26] and could explain the variation of burrow density between our nine community forests. We recorded most of 
the burrows at an elevation range of 1401 - $1500 \mathrm{~m}$. Suwal et al. [18] recorded the maximum occurrence of burrows of Chinese Pangolins at an elevation range of 1500 - $1844 \mathrm{~m}$ in Nepal. A study in China by Wu et al. [10] recorded most burrows at an elevation range of $750-1500 \mathrm{~m}$ and fewer burrows at $1501-1700$ m. In Nepal, though sympatric distribution is recorded for Chinese Pangolin and Indian Pangolin [20], Indian Pangolin burrows are recorded at an elevation of $675 \mathrm{~m}$ [18]. The predicted elevation ranged from $132 \mathrm{~m}$ to $2704 \mathrm{~m}$ for both Pangolins [18] and the greatest potential distribution of Chinese Pangolin is in the mid-hill region between 1000 - $3000 \mathrm{~m}$ in Nepal [17]. We have conducted our study in a relatively small area (170.69 ha) and could not include samples from a wide range of elevation, so elevation preference may not be applicable to other Chinese Pangolin habitats.

All burrows in our study area were on gentle slopes $\left(<30^{\circ}\right)$. This finding contrasts with the finding of Wu et al. [10] who reported that Chinese Pangolins in China prefer steeper slopes because digging burrows in steep slopes save energy for Chinese Pangolins as well as reducing damage to burrow entrance from heavy rainfall [3]. Heath et al. [27] also noted that high energy consumption is required in digging burrows. However, studies carried out by Bhandari and Chalise [11] and Rai [28] reported the maximum number of burrows at $20^{\circ}-30^{\circ}$ in Nepal. Rai [28] recorded the presence of soft clay loam and sandy loam soil in a slope gradient of $20^{\circ}-30^{\circ}$ in community forests of Dolakha district, midhills Nepal. Chinese Pangolins chose soft, layered soil to dig burrows [22]. Unlike Chinese Pangolins, Indian Pangolins have been reported to prefer burrowing at slopes of $40^{\circ}-50^{\circ}[18]$ and $30^{\circ}-60^{\circ}[12]$.

We found that most burrow sites had a southern exposure, which is consistent with $\mathrm{Wu}$ et al. [10] who reported that Chinese Pangolins in China prefer burrowing entrance exposure facing the sun (i.e., south direction), which helps to maintain burrow temperature in winter. Our survey was conducted during winter, which is when a southern exposure would be helpful. Chinese Pangolins have slow metabolisms, so an optimum temperature of at least $18^{\circ} \mathrm{C}$ during winter should be present to keep these animals warm inside their burrows [3] [29]. We observed that $90 \%$ of the burrows had internal temperatures less than $20^{\circ} \mathrm{C}$, and we recorded difference between the inside and outside burrow temperatures. However, Bao et al. [29] in a study of air temperature changes in burrows of Chinese Pangolin reported that the outside temperature of a burrow does not have a significant impact on the thermal conditions of Chinese Pangolins inside burrows.

Our finding that Chinese Pangolins prefer burrow sites with moderate to dense vegetation is consistent with other studies. Chinese Pangolins have poor defense mechanism against predators [8] and prefer dense ground cover for locomotion, feeding, protecting their cubs and protecting their burrow entrance [10] [21]. Dense undergrowth vegetation serves as insulation and helps to protect juvenile Chinese Pangolins from cold temperatures during the winter [10]. 
Similarly, we recorded that Chinese Pangolin prefer burrow sites with moderate to dense canopy closure, which is similar to other studies [10] [18]. Termite and ant species, which are common prey of Chinese Pangolin, are more common in dense forest canopies [30]. However, in some habitats having open canopy closure and dense undergrowth vegetation could discourage pangolins from making living burrows in those habitats [12].

We found that most burrows were located in sites with brown soil and low soil moisture $(0 \%-15 \%)$, which is consistent with other studies [11] [15] [16] [31]. Chinese Pangolin's preferred food is termites, which tend to colonize in moist soils because of higher moisture content making the soil soft and easier to dig burrows [3] [32]. Chinese Pangolins have been reported to feed on 23 species of ants and 12 species of termites [24] and consume all life stages of these preys [33]. However, we acknowledge that soil moisture fluctuates in burrows, and we were not able to record soil moisture on multiple days.

Most of the burrows in our study area were less than $200 \mathrm{~m}$ from human settlements since community forests are generally located near villages. In turn, community forests are often located near cultivated land, which are rich in ants and termites, so most of the burrows were recorded close to human settlement. Cultivated areas are considered as potential habitat for Chinese Pangolins in Nepal [17]. Other studies have reported that anthropogenic activities have a negative impact on Chinese Pangolin survival near human settlements [26] and that collection of fuel wood and fodder, grazing livestock inside the community forest, spraying insecticides and pesticides in agricultural lands close to community forests are major threats to Chinese Pangolins [34]. Most of the burrows in our study area were less than $150 \mathrm{~m}$ from a stream because two major rivers, Rosi and Ladku, as well as many small streams are present in the area. Our finding was consistent with other studies that report that Chinese Pangolins drink water frequently [16] and that Chinese Pangolin burrows are rarely found in dry areas [11].

Our study analyzed a larger number of burrows than any previous study in Nepal and has provided a detailed ecological understanding of Chinese Pangolin burrows in association with different environmental variables in community forests in Nepal. We found that Chinese Pangolins prefer burrowing at elevations between 1401 - $1500 \mathrm{~m}$ in sites with gentle slopes, high forest canopy, high undergrowth, brown soil, southern exposure, and do not prefer sites with higher elevation, steep slopes, northern exposure, low crown cover and low undergrowth vegetation. Our findings will help conservation agencies to support the community forest user groups in developing strategic measures to conserve Chinese Pangolins. We recommend that additional studies involving modern scientific techniques, such as camera traps and genetic studies, be conducted to assess the status, distribution and population size of Chinese Pangolins in these areas and throughout their range, in order to conserve the most highly trafficked mammal species in the world. 


\section{Acknowledgements}

This study was conducted supported by a Current and Aspiring faculty award for Ph.D. study received from Russell E Train Education of Nature Program (EFN), World Wildlife Fund (WWF), USA. We would also like to thank University Grant Commission, Nepal (Collaborative Research Grant 2074-75) and Columbus Zoos and Aquarium Conservation Fund, the USA for providing funds to conduct this study; the Department of Forests and Soil Conservation, Nepal, District Forest Office and Community Forest User's group, Kavrepalanchok for providing permission to conduct the study; and the Department of Environmental Science and Engineering, Kathmandu University, Nepal and University of Rhode Island, the USA for supporting the study.

\section{Conflicts of Interest}

The authors declare no conflicts of interest regarding the publication of this paper.

\section{References}

[1] Challender, D., Wu, S., Kaspal, P., Khatiwada, A., Ghose, A., Sun, N.C.-M., Mohapatra, R.K. and Suwal, T.L. (2019) Manis pentadactyla (Errata Version Published in 2020). The IUCN Red List of Threatened Species, 2019, e.T12764A168392151.

[2] Heath, M. (1992) Manis pentadactyla. Mammalian Species, 414, 1-6. https://doi.org/10.2307/3504143

[3] Hua, L., Gong, S., Wang, F., Li, W., Ge, Y., Li, X. and Hou, F. (2015) Captive Breeding of Pangolins: Current Status, Problems and Future Prospects. ZooKeys, 507, 99-114. https://doi.org/10.3897/zookeys.507.6970

[4] CITES (2017) Convention on International Trade in Endangered Species of Wild Fauna and Flora-Notification to the Parties No. 2016/007. New Annual Illegal Trade Report, Geneva. https://cites.org/eng/app/appendices.php

[5] Thapa, P., Khatiwada, A.P., Nepali, S.C. and Paudel, S. (2014) Distribution and Conservation Status of Chinese pangolin (Manis pentadactyla) in Nangkholyang VDC, Taplejung, Eastern Nepal. American Journal of Zoological Research, 2, 16-21.

[6] Katuwal, H.B., Neupane, K.R., Adhikari, D., Sharma, M. and Thapa, S. (2015) Pangolins in Eastern Nepal: Trade and Ethno-Medicinal Importance. Journal of Threatened Taxa, 7, 7563-7567. https://doi.org/10.11609/JoTT.o4202.7563-7

[7] Dahal, D., Gautam, D., Bhattarai, S., Khanal, L., Baral, K. and Raj, K. (2019) Potentiality of Pangolin based Ecotourism in Chuchhekhola Community Forest, Makawanpur, Nepal. Journal of Emerging Technologies and Innovative Research, 6, 250-257.

[8] Liu, Z.H. and Xu, L.H. (1981) Pangolin's Habits and Its Resource Protection. Chinese Journal of Zoology, 16, 40-41.

[9] Shi, Y.Q. (1985) Feeding Habits on Chinese Pangolin (Manis pentadactyla). Chinese Wildlife, 6, 11-13.

[10] Wu, S.B., Liu, N.F., Ma, G.Z., Xu, Z.R. and Chen, H. (2003) Habitat Selection by Chinese Pangolin (Manis pentadactyla) in Winter in Dawuling Natural Reserve. Mammalia, 67, 493-502. https://doi.org/10.1515/mamm-2003-0403

[11] Bhandari, N. and Chalise, M.K. (2014) Habitat and Distribution of Chinese Pango- 
lin (Manis pentadactyla Linnaeus, 1758) in Nagarjun Forest of Shivapuri Nagarjun National Park, Nepal. Nepalese Journal of Zoology, 2, 18-25.

[12] Karawita, H., Perera, P., Gunawardane, P. and Dayawansa, N. (2018) Habitat Preference and Den Characterization of Indian Pangolin (Manis crassicaudata) in a Tropical Lowland Forested Landscape of Southwest Sri Lanka. PLoS ONE, 13, e0206082. https://doi.org/10.1371/journal.pone.0206082

[13] Acharya, P., Rana, K., Devkota, M. and Gurung, Y. (1993) A Report on Conservation Status of Pangolins in the Protected Forest of Nagarjune. Tiger Paper, 3, 35-38.

[14] Gurung, J.B. (1996) A Pangolin Survey in Royal Nagarjung Forest in Kathmandu, Nepal. Tiger Paper, 23, 29-32.

[15] Kaspal, P. (2008) Status, Distribution, Habitat Utilization and Conservation of Chinese Pangolin in the Community Forests of Suryabinayak Range Post, Bhaktapur District. M.Sc. Thesis, Khowpa College, T.U Affiliated, Nepal.

[16] Suwal, T.L. (2011) Status, Distribution, Behaviour and Conservation of Pangolins in Private and Community Forests of Balthali in Kavre, Nepal. M.Sc. Thesis, Tribhuwan University, Kirtipur.

[17] Sharma, H.P., Rimal, B., Zhang, M., Sharma, S., Poudyal, L.P., Maharjan, S., Kunwar, R., Kaspal, P., Bhandari, N., Baral, L., Dhakal, S., Tripathi, A., Karki, N., Khadki, B., Thapa, P., Acharya, B.K., Acharya, S., Baral, K. and Katuwal, H.B. (2020) Potential Distribution of the Critically Endangered Chinese Pangolin (Manis pentadactyla) in Different Land Covers of Nepal: Implications for Conservation. Sustainability, 12, 1282. https://doi.org/10.3390/su12031282

[18] Suwal, T.L., Thapa, A., Gurung, S., Aryal, P.C., Basnet, H., Basnet, K., Shah, K.B., Thapa, S., Koirala, Dahal, S., Katuwal, H.B., et al. (2020) Predicting the Potential Distribution and Habitat Variables Associated with Pangolins in Nepal. Global Ecology and Conservation, 23, e01049. https://doi.org/10.1016/j.gecco.2020.e01049

[19] Buffum, B., Shrestha, S. and Husband, T. (2020) Assessment of Community-Based Activities to Reduce Human-Elephant Conflict in Nepal. In: Wang, Y., Ed., The Handbook of Natural Resources. Terrestrial Ecosystem and Biodiversity, 2nd Edition, Taylor and Francis, 1-15. https://doi.org/10.1201/9780429445651-2

[20] DNPWC (2019) Pangolin Monitoring Guideline for Nepal. Department of National Parks and Wildlife Conservation, Ministry of Forests and Environment, Kathmandu.

[21] Dorji, D. (2017) Distribution, Habitat Use, Threats and Conservation of the Critically Endangered Chinese Pangolin (Manis pentadactyla) in Samtse District, Bhutan. Rufford Small Grants, UK. (Unpublished)

[22] Wu, S., Ma, G., Chen, H., Xu, Z., Li, Y. and Liu, N. (2004) A Preliminary Study on Burrow Ecology of Manis pentadactyla. Ying Yong Sheng Tai Xue Bao (The Journal of Applied Ecology), 15, 401-407.

[23] Willcox, D., Nash, H.C., Trageser, S., Kim, H.J., Hywood, L., Connelly, E., Ichu, G.I., Nyumu, J.K., Moumbolou, C.L.M., Ingram, D.J. and Challender, D.W. (2019) Evaluating Methods for Detecting and Monitoring Pangolin (Pholidata: Manidae) Populations. Global Ecology and Conservation, 17, e00539.

https://doi.org/10.1016/j.gecco.2019.e00539

[24] Wu, S., Sun, N.C.M., Zhang, F., Yu, Y., Ades, G., Suwal, T.L. and Jiang, Z. (2020) Chinese Pangolin Manis pentadactyla (Linnaeus, 1758). In: Challender D., Nash, H.C. and Waterman, C., Eds., Pangolins: Science, Society and Conservation, Academic Press, 49-70. https://doi.org/10.1016/B978-0-12-815507-3.00004-6

[25] Trageser, S.J., Ghose, A., Faisal, M., Mro, P., Mro, P. and Rahman, S.C. (2017) Pan- 
golin Distribution and Conservation Status in Bangladesh. PLoS One, 12, e0175450. https://doi.org/10.1371/journal.pone.0175450

[26] Katuwal, H.B., Sharma, H.P. and Parajuli, K. (2017) Anthropogenic Impacts on the Occurrence of the Critically Endangered Chinese Pangolin (Manis pentadactyla) in Nepal. Journal of Mammalogy, 98, 1667-1673.

https://doi.org/10.1093/jmammal/gyx114

[27] Heath, M.E. and Vanderlip, S.L. (1988) Biology, Husbandry, and Veterinary Care of Captive Chinese Pangolins (Manis pentadactyla). Zoo Biology, 7, 293-312. https://doi.org/10.1002/zoo.1430070402

[28] Rai, A. (2018) Distribution and Habitat Assessment of Chinese Pangolins (Manis pentadactyla, Linnaeus, 1758) in Dolakha, Nepal. M.Sc. Thesis, Kathmandu University, Kathmandu.

[29] Bao, F., Wu, S., Su, C., Yang, L., Zhang, F. and Ma, G. (2013) Air Temperature Changes in a Burrow of Pangolin, Manis pentadactyla, in Winter. Journal of Vertebrate Biology, 62, 42-47. https://doi.org/10.25225/fozo.v62.i1.a6.2013

[30] Axelsson, E.P. (2012) A Case Study of Termite Mound Occurrence in Relation to Forest Edges and Canopy Cover within the Barandabhar Forest Corridor in Nepal. International Journal of Biodiversity and Conservation, 4, 633-641.

[31] Bhandari, N. (2017) Distribution, Habitat Utilization and Threats to Chinese Pangolin (Manis pentadactyla, 1758) in Eastern Chure, Nepal. M.Sc. Thesis, Tribhuvan University, Kirtipur.

[32] Cornelius, M.L. and Osbrink, W.L.A. (2010) Effect of Soil Type and Moisture Availability on the Foraging Behavior of the Formosan Subterranean Termite (Isoptera: Rhinotermitidae). Journal of Economic Entomology, 103, 799-807. https://doi.org/10.1603/EC09250

[33] Fang, L.X. and Wang, S. (1980) A Preliminary Survey on the Habits of Pangolin. Memoirs of Beijing Natural History Museum, 7, 1-6.

[34] Acharya, S., Rayamajhi, S., Sharma, S., Upadhaya, S. and Joshi, S. (2018) Anthropogenic Threats to Survival of the Critically Endangered Chinese Pangolins (Manis pentadactyla) and Their Habitat in Kavrepalanchowk Nepal. Journal of Biodiversity \& Endangered Species, 6, 2. 